\title{
MAXIMAL COORDINATE DISCREPANCY AS ACCURACY CRITERION OF IMAGE PROJECTIVE NORMALIZATION FOR OPTICAL RECOGNITION OF DOCUMENTS
}

\author{
I.A. Konovalenko ${ }^{1,2}$, V.V. Kokhan ${ }^{1,2}$, D.P. Nikolaev ${ }^{1,2}$ \\ ${ }^{1}$ Institute for Information Transmission Problems of the RAS, Moscow, \\ Russian Federation \\ ${ }^{2}$ Smart Engines Service LLC, Moscow, Russian Federation \\ E-mails: konovalenko@smartengines.com, v.kokhan@smartengines.com,dimonstr@iitp.ru
}

\begin{abstract}
Application of projective normalization (a special case of orthocorrection and perspective correction) to photographs of documents for their further optical recognition is generally accepted. In this case, inaccuracies of normalization can lead to recognition errors. To date, a number of normalization accuracy criteria are presented in the literature, but their conformity with recognition quality was not investigated. In this paper, for the case of a fixed structured document, we justify a uniform probabilistic model of recognition errors, according to which the probability of correct recognition of a character abruptly falls to zero with an increase in the coordinate discrepancy of this character. For this model, we prove that the image normalization accuracy criterion, which is equal to the maximal coordinate discrepancy in the text fields of a document, monotonously depends on the probability of correct recognition of the entire document. Also, we show that the problem on computing the maximal coordinate discrepancy is not reduced to the nearest known one, i.e. the linearfractional programming problem. Finally, for the first time, we obtain an analytical solution to the problem on computing the maximal coordinate discrepancy on a union of polygons.

Keywords: orthocorrection; perspective correction; image projective normalization; optical character recognition; accuracy criteria; coordinate discrepancy; nonlinear programming.
\end{abstract}

\section{Introduction}

\section{Image Projective Normalization}

Using calibration [1], almost any imaging optical system (hereinafter referred to as a camera) can be reduced to an orthoscopic one, i.e. a system satisfying a projective model of a camera [2]. In the framework of this model, an arbitrary scene plane is associated with the image plane by a projective transformation.

A shooting angle with respect to the flat scene is called normal if the imaging optical system is oriented normal to the scene. The projective transformation of an image taken from an arbitrary angle ensures an imitation of an image taken from a virtual normal angle based on the image taken from an arbitrary angle. Following [3], we refer to such an imitation as an image projective normalization (IPN). An image obtained as a result of IPN is called normalized. A normalized image is orthoscopic, i.e. the image of a flat scene on the normalized image is similar to the scene itself. This fact fundamentally simplifies further analysis of the scene. As a rule, IPN requares not only consider the virtual camera angle to be normal, but also fix some of remaining degrees of freedom of the camera (solid body), which appear as isotropic scaling, shift, and orientation of the normalized image.

Projective normalization is actively used as a stage of image preprocessing for solving various problems of technical vision such as recognition of text content of documents [4-8], car number recognition [9], automatic recognition of a television program by a 
picture of TV screen [10], checkerboard detection to calibrate a camera [11], detection of artificial roughness on roads [12], matching of the contour of an object represented in the image with an object in the database [13-18], satellite monitoring (estimation of temporal variability of the ocean surface temperature, determination of the speed of movement of cloud masses, etc.) [19], drawing up plans and maps of the area based on the results of aerial photography [20,21], etc. In addition, projective normalization of a photograph of a document is applicable to facilitate perception by a person [22].

\section{Accuracy Criteria of Image Normalization}

As shown above, IPN is used as a stage of image preprocessing for solving many problems of technical vision. Any IPN methods work with errors, and the properties of these errors are different for different methods. Therefore, for different problems taking place in technical vision, different IPN methods may be preferable from the point of view of the quality of solution. In order to select or develop an optimal method for specific problems, appropriate problem-oriented criteria for the accuracy of IPN are needed. A large number of normalization accuracy criteria are proposed in the literature, but the question of their focus on solving particular computer vision problems was not investigated. This casts doubt on correspondence of the developed IPN methods to the problems facing the methods. In this paper, we aim to fill this gap.

\section{Definitions and Notations}

Let $I_{\text {input }}$ be an image for projective normalization, which is a photograph usually. Assume that the projective transformation $\mathrm{H}$, which defines the ideal normalization of the image $I_{\text {input }}$, is known. We consider only cases when $\mathrm{H}$ is unique. Such a transformation is set expertly and is used as an ideal answer when testing IPN methods. Let $I_{\text {ideal }}$ be the ideally normalized image formed as a result of applying $\mathrm{H}$ to $I_{\text {input }}$ (see Fig. 1), $\hat{\mathrm{H}}$ be the estimate of the transformation $\mathrm{H}$ obtained by the IPN method, and $I_{\text {pract }}$ be the practically normalized image formed by applying $\hat{\mathrm{H}}$ to $I_{\text {input }}$.

Denote by $\mathbf{r} \stackrel{\text { def }}{=}\left[\begin{array}{ll}x & y\end{array}\right]^{T}$ the Cartesian coordinates of pixels on the plane of the image $I_{\text {ideal }}$. Also, define the residual projective transformation $\mathrm{V} \stackrel{\text { def }}{=} \hat{\mathrm{H}} \mathrm{H}^{-1}$, which, for each point of the scene, associates the coordinates $\mathbf{r}$ of the image of the point on $I_{\text {ideal }}$ with the coordinates $\mathrm{V}(\mathbf{r})$ of the image of the point on $I_{\text {pract }}$. In order to formalize the point-by-point error of the IPN, we introduce the coordinate discrepancy [23] (see Fig. 2):

$$
\mathrm{d}(\mathbf{r}) \stackrel{\text { def }}{=}\|\mathbf{r}-\mathrm{V}(\mathbf{r})\|_{2} \text {. }
$$

In this paper, for brevity, we sometimes refer to the coordinate discrepancy as a discrepancy. Denote by $R \subset \mathbb{R}^{2}$ the region of interest, i.e. the previously known set of the points of $I_{\text {ideal }}$ occupied by the image of the scene's target object (document or its parts, car number, building, etc.).

\section{Justification of Maximal Coordinate Discrepancy as Accuracy Criterion of Image Normalization}

\subsection{Optical Recognition of Fixed Structured Documents}

By the problem on optical recognition of a document we mean the problem on recognizing textual content of the document on the basis of a photograph taken from an arbitrary angle [24], i.e. in the presence of significant projective distortion. 


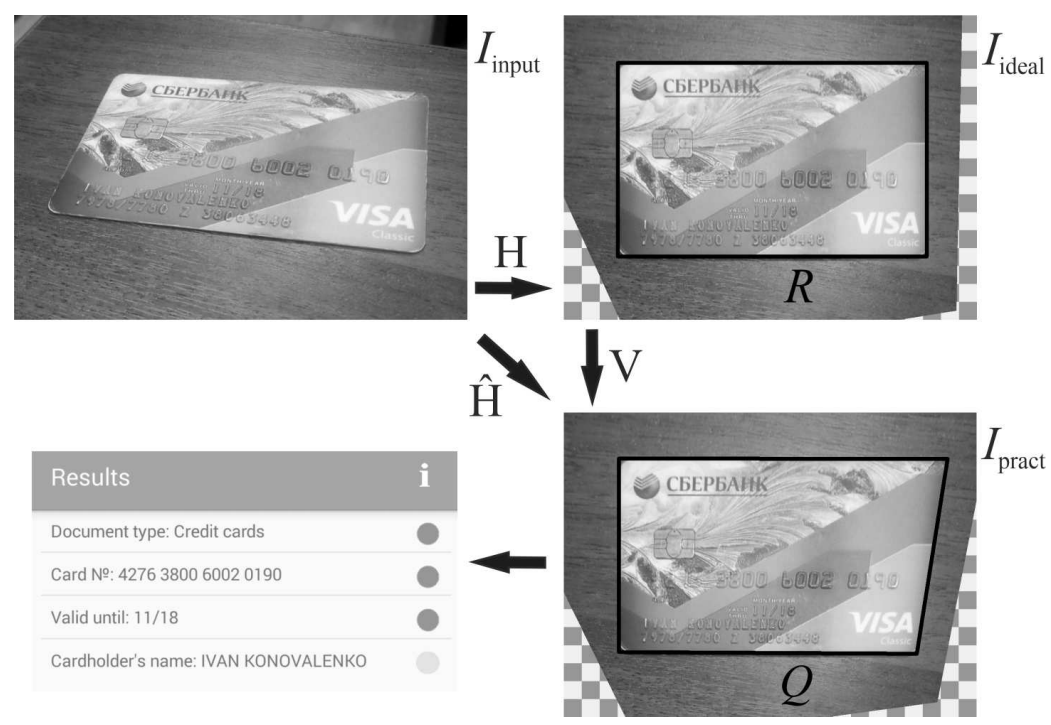

Fig. 1. General scheme of transformations, where $I_{\text {input }}$ is a photograph of a document taken from an arbitrary angle, $I_{\text {ideal }}$ is the ideally normalized image, $I_{\text {pract }}$ is the practically normalized image and its recognition
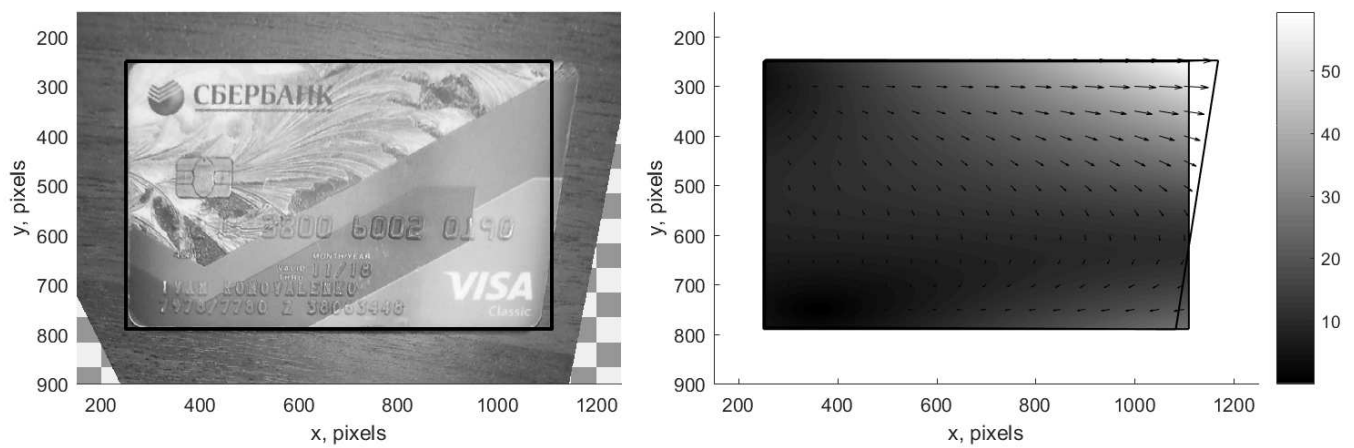

Fig. 2. Coordinate discrepancy. Left: $I_{\text {pract }}$ is the almost normalized image, where the region of interest $R$ is bounded by the frame. Right: $\mathrm{V}(\mathbf{r})-\mathbf{r}, \mathbf{r} \in R$, is the displacement vector field, where coordinate discrepancy $d(\mathbf{r})$ is shown in shades of gray

We say that a document is fixed structured, if text content of the document is grouped into text fields with a known font size and position on the document. Fixed structured documents include bank cards, driver's license, national and foreign passports, insurance certificates, birth certificates, ID cards, plastic passes, etc. A priori knowledge of the fixed structure of a document significantly improves the quality of recognition. For brevity, we refer to the problem on optical recognition of fixed structured documents as the recognition problem (see Fig. 1). A system that solves the recognition problem is called a recognition system.

\subsection{Decomposition of Recognition System}

As a rule, a recognition system is decomposed into two modules $[5,7,8]$. Based on the input image $I_{\text {input }}$, the image projective normalization module calculates the estimate $\hat{\mathrm{H}}$ of the ideal projective normalization $\mathrm{H}$ and applies $\hat{\mathrm{H}}$ to the image $I_{\text {input }}$ in order to form the 
almost normalized image $I_{\text {pract }}$ (see Fig. 1). The recognition module receives the almost normalized image $I_{\text {pract }}$ as input and returns text content of the document fields.

\subsection{Uniform Probabilistic Model of Recognition Errors}

Let $\mathbf{r}$ be coordinates of an arbitrary document character in the image $I_{\text {ideal }}$, then $\mathrm{V}(\mathbf{r})$ are coordinates of the character in the image $I_{\text {pract }}$. At the same time, for the recognition module, the coordinates $\mathbf{r}$ are known and represent the expected position of the character, and $\mathrm{V}(\mathbf{r})$ represent the unknown actual position of the character. Then the coordinate discrepancy $\mathrm{d}(\mathbf{r})=\|\mathbf{r}-\mathrm{V}(\mathbf{r})\|_{2}(1)$ for the character with the coordinates $\mathbf{r}$ corresponds to the distance between the expected and actual positions of the character in the normalized image $I_{\text {pract }}$. Then the probability $p$ of correct recognition of a character decreases with an increase in the discrepancy $d$ of this character. Character recognition takes place locally in some window of the image $I_{\text {pract }}$ called a recognition window, whose dimensions slightly exceed the size of the character itself. If a character does not belong to the recognition window, then the character can not be recognized. In the simple case, the recognition window takes place at the coordinates $\mathbf{r}$ of the expected character position. But in view of the fact that the documents do not ideally correspond to the known predetermined structure, the recognition module can specify the position of the recognition window within certain limits. In both cases, we assume that the probability $p$ of correct recognition of a character remains constant up to a certain value of the discrepancy d, and then falls to zero:

$$
p(\mathrm{~d})=p_{0}\left[\mathrm{~d} \leq \mathrm{d}_{0}\right],
$$

where [•] is the Iverson bracket. Such a probabilistic model of recognition errors is called uniform.

\subsection{Statement of Problem on Constructing an Accuracy Criterion of Image Normalization}

In accordance with the modular principle, development of the projective normalization module should be possible in the absence of the recognition module. To this end, it is necessary to construct an accuracy criterion of normalization

$$
L=L\left(\hat{\mathrm{H}}, \mathrm{H}, \mathrm{V}, \mathrm{d} ; I_{\text {pract }}, I_{\text {ideal }} ; R\right),
$$

such that the probability $P$ of correct recognition of the entire document depends on $L$ monotonically decreasing. Fulfillment of this requirement leads to an improvement in the quality of recognition with a decrease in the value $L$.

\subsection{Construction of Accuracy Criterion of Image Normalization}

Each character is recognized independently, therefore, the probability of correct recognition of the entire document is $P=\prod_{i=1}^{n} p_{i}$, where $p_{i}=p\left(\mathrm{~d}_{i}\right)$ is the probability of correct recognition of the $i$-th character. Using uniform probabilistic model (2), we obtain

$$
P=\prod_{i=1}^{n} p_{0}\left[\mathrm{~d}_{i} \leq \mathrm{d}_{0}\right]=p_{0}^{n}\left[\max _{i} \mathrm{~d}_{i} \leq \mathrm{d}_{0}\right]
$$


Taking the maximal coordinate discrepancy over all characters of the document $\max _{i} \mathrm{~d}_{i}$ as the criterion $L$, we have the monotonously decreasing dependence of $P$ on $L$ : $P=p_{0}^{n}\left[L \leq \mathrm{d}_{0}\right]$. This fact solves the considered problem at any values of the parameters $\mathrm{d}_{0}$ and $p_{0}$. Since text fields include those and only those areas of the image where recognizable characters are located, we use $\max _{\mathbf{r} \in R} \mathrm{~d}(\mathbf{r})$ instead of $\max _{i} \mathrm{~d}_{i}$. In this case, the region of interest $R$ is the set of points of the image $I_{\text {ideal }}$ on which the text fields are located.

Therefore, the desired accuracy criterion of normalization is the minimax criterion equal to the maximal coordinate discrepancy on the region of interest $R$ :

$$
L=L_{\infty}(\mathrm{d} ; R) \stackrel{\text { def }}{=} \max _{\mathbf{r} \in R} \mathrm{~d}(\mathbf{r}) .
$$

This criterion was used in [19] to calculate the accuracy of automatic linking of images obtained from a geostationary satellite.

\section{Calculation of Maximal Coordinate Discrepancy}

In this section, we construct an analytical solution to the problem on calculating the maximal coordinate discrepancy $L_{\infty}(\mathrm{d} ; R)=\max _{\mathbf{r} \in R} \mathrm{~d}(\mathbf{r})$ for the only important case from the point of view of the technical vision when the region of interest $R$ consists of polygons, i.e. $R$ is a two-dimensional polyhedron. Following the terminology of mathematical programming, the coordinate discrepancy $\mathrm{d}$ is called the objective function, and the region of interest $R$ is called the admissible set. We define the residual projective transformation $\mathrm{V}$ in Cartesian coordinates by the homogeneous homography matrix $V \stackrel{\text { def }}{=}\left(v_{i j}\right) \in \mathbb{R}^{3 \times 3}$ :

$$
\mathrm{V}(\mathbf{r}) \stackrel{\text { def }}{=} \frac{\left[\begin{array}{l}
v_{11} x+v_{12} y+v_{13} \\
v_{21} x+v_{22} y+v_{23}
\end{array}\right]}{v_{31} x+v_{32} y+v_{33}} .
$$

Denote by $\mathbf{l}_{\infty}$ the horizon, i.e. the line on the plane of the image $I_{\text {ideal }}$ having the equation $v_{31} x+v_{32} y+v_{33}=0$. The denominator of the transformation $\mathrm{V}$ is 0 on $\mathbf{l}_{\infty}$ and only on $\mathbf{l}_{\infty}$ (see equation (4)). For definiteness, assume that

$$
\mathbf{r} \in \mathbf{l}_{\infty} \Longrightarrow \mathrm{d}(\mathbf{r}) \stackrel{\text { def }}{=}+\infty .
$$

Now we describe the problem on calculating the maximal coordinate discrepancy (3):

$$
L_{\infty}(\mathrm{d} ; R)=\max \left\|\left[\begin{array}{l}
x-\frac{v_{11} x+v_{12} y+v_{13}}{v_{31} x+v_{32} y+v_{33}} \\
y-\frac{v_{21} x+v_{22} y+v_{23}}{v_{31} x+v_{32} y+v_{33}}
\end{array}\right]\right\|_{2}, \quad\left[\begin{array}{l}
x \\
y
\end{array}\right] \in R .
$$

In this problem, the objective function is neither linear fractional, nor (quasi) convex, nor (quasi) concave (see Fig. 2). Therefore, problem (6) belongs to the general class of nonlinear programming problems only [25]. The linear fractional programming (LFP) problem [26]

$$
\max \left(\frac{v_{11} x+v_{12} y+v_{13}}{v_{31} x+v_{32} y+v_{33}}\right), \quad\left[\begin{array}{l}
x \\
y
\end{array}\right] \in R
$$

is the closest to (6) known problem. Let us solve problem (6). 


\subsection{Maximal Coordinate Discrepancy on Bounded Closed Region of Interest in Affine Case}

Consider a particular case of problem (6), when the transformation $\mathrm{V}$ is affine.

Theorem 1. Let $\mathrm{V}$ be an affine transformation of the Euclidean plane $\mathbb{R}^{2}, R \subset \mathbb{R}^{2}$ be a nonempty bounded closed set. Then the maximum of the function $\mathrm{d}(\mathbf{r})=\|\mathbf{r}-\mathrm{V}(\mathbf{r})\|_{2}(1)$ on the set $R$ is achieved on the set of extreme points of the convex hull $\mathrm{E}(\operatorname{Conv}(R))$ of the set $R$ :

$$
\max _{R} \mathrm{~d}=\max _{\mathrm{E}(\operatorname{Conv}(R))} \mathrm{d}
$$

Proof. Since the transformation V is affine, then the function d is convex on $\mathbb{R}^{2}$. Therefore, the statement is a particular case of Theorem 4 (see Appendix A).

Now consider our particular case when $R$ consists of polygons. The convex hull of a union of polygons is a polygon. The extreme points of a polygon are its vertices $\left\{\mathbf{r}_{i}\right\}_{i=1}^{n}$. Therefore, according to (8),

$$
\max _{R} \mathrm{~d}=\max _{\left\{\mathbf{r}_{i}\right\}_{i=1}^{n}} \mathrm{~d}
$$

The asymptotic complexity of computing (9) is $\Theta(n)$ operations.

\subsection{Failure to Achieve Maximal Coordinate Discrepancy at Extreme Points of Convex Hull of Bounded Closed Region of Interest in Projective case}

The natural question is whether Theorem 1 remains true in the case when the residual transformation $\mathrm{V}$ is projective. The answer is no. In order to illustrate this fact, consider the following counterexample (see Fig. 3). Let

$$
V=\left[\begin{array}{ccc}
2 & 0 & 0 \\
-1 & 2 & 4 \\
-2 & 0 & 10
\end{array}\right] \Longrightarrow \mathrm{V}(\mathbf{r})=\frac{1}{-2 x+10}\left[\begin{array}{c}
2 x \\
-x+2 y+4
\end{array}\right]
$$

and the region of interest be the rectangle $R=[0,4] \times[0,1]$, then the extreme points of the convex hull of $R$ are $\mathrm{E}(\operatorname{Conv}(R))=\left\{\left[\begin{array}{l}0 \\ 0\end{array}\right],\left[\begin{array}{l}4 \\ 0\end{array}\right],\left[\begin{array}{l}4 \\ 1\end{array}\right],\left[\begin{array}{l}0 \\ 1\end{array}\right]\right\}$. Then the maximal coordinate discrepancy on $R$ exceeds the maximal coordinate discrepancy on $\mathrm{E}(\operatorname{Conv}(R))$ :

$$
\begin{gathered}
\max _{R} \mathrm{~d} \geq \mathrm{d}\left(\left[\begin{array}{l}
2 \\
1
\end{array}\right] \in R\right)=\frac{\sqrt{17}}{3}>0.4=\max _{\mathrm{E}(\operatorname{Conv}(R))} \mathrm{d} \Longrightarrow \\
\max _{R} \mathrm{~d}>\max _{\mathrm{E}(\operatorname{Conv}(R))} \mathrm{d},
\end{gathered}
$$

which contradicts statement (8) of Theorem 1. Therefore, in the projective case, the solution to problem $(6)$ is not necessarily achieved on $\mathrm{E}(\operatorname{Conv}(R))$. However, the solution to LFP problem (7) is necessarily achieved $[27,28]$. In this sense, problem (6) is not reduced to LFP problem (7). 


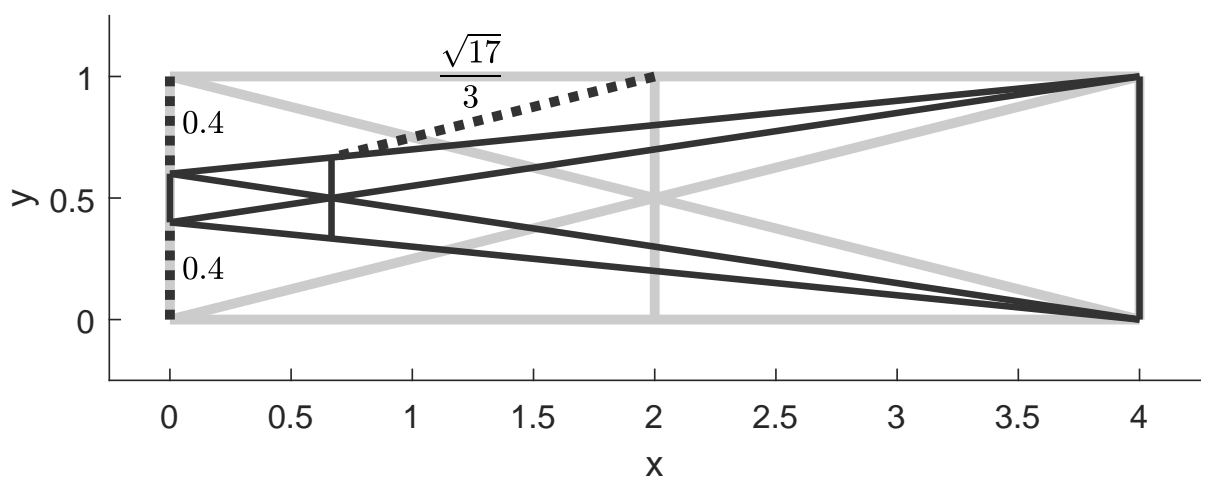

Fig. 3. Counterexample to the hypothesis of achieving maximal coordinate discrepancy at extreme points of the convex hull of a bounded closed admissible set in the projective case

\subsection{Maximal Coordinate Discrepancy on Bounded Closed Region of Interest in Projective Case}

As shown above, Theorem 1 is not true in the case when the residual transformation $\mathrm{V}$ is projective. However, for such a case, the following theorem is true.

Theorem 2. Let $\mathrm{V}$ be a projective transformation of the projective plane $\mathbb{R} \mathrm{P}^{2}, R \subset \mathbb{R} \mathrm{P}^{2}$ be a nonempty bounded closed set. Then the maximum of the function $\mathrm{d}(\mathbf{r})=\|\mathbf{r}-\mathrm{V}(\mathbf{r})\|_{2}$ on the set $R$ is achieved on the boundary $\partial R$ of the set $R$ :

$$
\max _{R} \mathrm{~d}=\max _{\partial R} \mathrm{~d}
$$

Proof. If the projective transformation $\mathrm{V}$ is affine, then statement (10) follows from Theorem 1. Consider the case when the projective transformation $\mathrm{V}$ is not affine. In this case, $v_{31}^{2}+v_{32}^{2}>0$. Introduce a family of parallel lines of the form $\mathbf{l}(c)=\left\{\mathbf{r}: v_{31} x+\right.$ $\left.v_{32} y+v_{33}=c\right\}$. The family covers the entire plane $\mathbb{R}^{2}$, therefore the desired maximum is achieved on a line that belongs to the family. Let $\mathbf{l}^{*} \stackrel{\text { def }}{=} \mathbf{l}\left(c^{*}\right)$ be such a line, $X \stackrel{\text { def }}{=} \mathbf{l}^{*} \cap R$ be the intersection of the line and $R$, then

$$
\max _{R} \mathrm{~d}=\max _{X} \mathrm{~d}
$$

Consider the properties of the function $\mathrm{d}$ on the line $\mathbf{l}^{*}$. If $c^{*}=0$, then $\mathrm{d}(\mathbf{r})=+\infty$ by definition (5). But the line $\mathbf{l}^{*}$ intersects the admissible set $R$, as well as its boundary $\partial R$ (since $R$ is bounded and closed), therefore the maxima of $\mathrm{d}$ on $R$ and on $\partial R$ are infinity, i.e. are equal. Next, consider the case of $c^{*} \neq 0$. Then, on the line $\mathbf{l}^{*}$, the function $\mathrm{d}$ is the root of a non-negative quadratic function (in the particular case, the latter function is a constant)

$$
\mathrm{d}(\mathbf{r})=\sqrt{\left(x-\frac{v_{11} x+v_{12} y+v_{13}}{c^{*}}\right)^{2}+\left(y-\frac{v_{21} x+v_{22} y+v_{23}}{c^{*}}\right)^{2}},
$$

i.e. $\mathrm{d}$ is convex. On the other hand, since $R$ is bounded and closed, then the set $X=\mathbf{l}^{*} \cap R$ is also bounded and closed. Then, by Theorem 4 (see Appendix A), the maximum of the 
function $\mathrm{d}$ on $X$ is achieved at the set of extreme points of the convex hull $\mathrm{E}(\operatorname{Conv}(X))$ that belong to the boundary $\partial R$ included in $R$, i.e.:

$$
\max _{X} \mathrm{~d}=\max _{\mathrm{E}(\operatorname{Conv}(X))} \mathrm{d} \leq \max _{\partial R} \mathrm{~d} \leq \max _{R} \mathrm{~d} .
$$

Note that $X$ is the set of segments along which the line $\mathbf{l}^{*}$ intersects the set $R$, then its convex hull $\operatorname{Conv}(X)$ is the segment as well, and $\mathrm{E}(\operatorname{Conv}(X))$ is the pair of its endpoints. Statement (10) follows from (11) and (12).

By analogy, we can prove that Theorem 2 is true for any finite dimension.

In the case of a bounded closed region of interest $R$, statement (10) of Theorem 2 allows to search for the maximal coordinate discrepancy only on the boundary $\partial R$ of the region of interest $R$.

\subsection{Maximal Coordinate Discrepancy on Union of Polygons}

Based on Theorems 1 and 2, we analytically calculate the maximal coordinate discrepancy on a union of polygons. Let $\mathrm{V}$ be a projective transformation of the projective plane $\mathbb{R P}^{2}, R \subset \mathbb{R P}^{2}$ be a union of polygons. The problem is to calculate analytically the maximal coordinate discrepancy $\mathrm{d}(\mathbf{r})=\|\mathbf{r}-\mathrm{V}(\mathbf{r})\|_{2}$ on $R(3)$ :

$$
L_{\infty}(\mathrm{d} ; R)=\max _{R} \mathrm{~d} .
$$

Let us solve this problem. If the projective transformation $\mathrm{V}$ is affine, then, following Theorem 1, the analytical solution is given by formula (9). Next, we consider the case when the projective transformation $\mathrm{V}$ is not affine. Then $v_{31}^{2}+v_{32}^{2}>0$ and there exists the horizon $\mathbf{l}_{\infty}$ on which the discrepancy $\mathrm{d}=+\infty$. If the horizon $\mathbf{l}_{\infty}$ intersects the set $R$, then $\mathbf{l}_{\infty}$ intersects the boundary $\partial R$ (since $R$ is bounded and closed), therefore $L_{\infty}(\mathrm{d} ; R)=+\infty$. Next, we consider the case when the horizon $\mathbf{l}_{\infty}$ does not intersect the set $R$. Then, following Theorem 2, we can replace original problem (3) on finding the maximum on the set $R$ with the problem on finding the maximum on the boundary $\partial R$ :

$$
L_{\infty}(\mathrm{d} ; R)=\max _{\partial R} \mathrm{~d} .
$$

But the boundary $\partial R$ of the union of polygons $R$ consists of the segments $\left\{S_{i}\right\}_{i=1}^{n}$, therefore

$$
L_{\infty}(\mathrm{d} ; R)=\max _{i} \max _{S_{i}} \mathrm{~d} .
$$

Denote $m_{i} \stackrel{\text { def }}{=} \max _{S_{i}} \mathrm{~d}$, then

$$
L_{\infty}(\mathrm{d} ; R)=\max _{i} m_{i}
$$

Therefore, problem (13) is reduced to the problem on finding the maximal coordinate discrepancy d on the segment $S: m=\max _{S} \mathrm{~d}$. Denote the endpoints of the segment $S$ by $\mathbf{r}_{1}=\left[\begin{array}{ll}x_{1} & y_{1}\end{array}\right]^{T}$ and $\mathbf{r}_{2}=\left[\begin{array}{ll}x_{2} & y_{2}\end{array}\right]^{T}$. Since the coordinate discrepancy is differentiable, then the maximum of the discrepancy on the segment $S$ is achieved either at the endpoints of $S$ or at the stationary points $\left\{\mathbf{r}_{j}^{*}\right\}_{j=1}^{J}$ of the squared discrepancy $\mathrm{d}^{2}$ :

$$
m=\max \left\{\mathrm{d}\left(\mathbf{r}_{1}\right), \mathrm{d}\left(\mathbf{r}_{2}\right), \quad \mathrm{d}\left(\mathbf{r}_{1}^{*}\right), \mathrm{d}\left(\mathbf{r}_{2}^{*}\right), \cdots, \mathrm{d}\left(\mathbf{r}_{J}^{*}\right)\right\} .
$$


Find the stationary points $\left\{\mathbf{r}_{j}^{*}\right\}_{j=1}^{J}$. After parametrization of the segment $S$ as the convex hull of its endpoints

$$
\mathbf{r}(t)=\left[\begin{array}{ll}
x(t) & y(t)
\end{array}\right]^{T}=\left(\mathbf{r}_{2}-\mathbf{r}_{1}\right) t+\mathbf{r}_{1}, \quad t \in[0,1]
$$

the squared discrepancy on the segment is written as follows:

$$
\mathrm{d}^{2}(t)=\left(x(t)-\frac{v_{11} x(t)+v_{12} y(t)+v_{13}}{v_{31} x(t)+v_{32} y(t)+v_{33}}\right)^{2}+\left(y(t)-\frac{v_{21} x(t)+v_{22} y(t)+v_{23}}{v_{31} x(t)+v_{32} y(t)+v_{33}}\right)^{2} .
$$

Denote

$$
\begin{aligned}
\Delta x & =x_{2}-x_{1}, & \Delta y & =y_{2}-y_{1}, \\
k_{x} & =v_{11} \Delta x+v_{12} \Delta y, & b_{x} & =v_{11} x_{1}+v_{12} y_{1}+v_{13}, \\
k_{y} & =v_{21} \Delta x+v_{22} \Delta y, & b_{y} & =v_{21} x_{1}+v_{22} y_{1}+v_{23}, \\
k_{z} & =v_{31} \Delta x+v_{32} \Delta y, & b_{z} & =v_{31} x_{1}+v_{32} y_{1}+v_{33}
\end{aligned}
$$

and obtain

$$
\mathrm{d}^{2}(t)=\left(\Delta x t+x_{1}-\frac{k_{x} t+b_{x}}{k_{z} t+b_{z}}\right)^{2}+\left(\Delta y t+y_{1}-\frac{k_{y} t+b_{y}}{k_{z} t+b_{z}}\right)^{2}
$$

In order to find stationary points, we equate the derivative to zero: $\frac{d\left(\mathrm{~d}^{2}(t)\right)}{d t}=0$,

$$
\left(\Delta x t+x_{1}-\frac{k_{x} t+b_{x}}{k_{z} t+b_{z}}\right)\left(\Delta x-\frac{k_{x} b_{z}-k_{z} b_{x}}{\left(k_{z} t+b_{z}\right)^{2}}\right)+\left(\Delta y t+y_{1}-\frac{k_{y} t+b_{y}}{k_{z} t+b_{z}}\right)\left(\Delta y-\frac{k_{y} b_{z}-k_{z} b_{y}}{\left(k_{z} t+b_{z}\right)^{2}}\right)=0
$$

Denote

$$
\begin{aligned}
h_{x 1} & =k_{z} \Delta x, \quad h_{x 2}=k_{z} x_{1}+b_{z} \Delta x-k_{x}, \quad h_{x 3}=b_{z} x_{1}-b_{x}, \\
h_{y 1} & =k_{z} \Delta y, \quad h_{y 2}=k_{z} y_{1}+b_{z} \Delta y-k_{y}, \quad h_{y 3}=b_{z} y_{1}-b_{y}, \\
h_{x 4} & =k_{z}^{2} \Delta x, \quad h_{x 5}=2 k_{z} b_{z} \Delta x, \quad h_{x 6}=k_{z} b_{x}-k_{x} b_{z}+b_{z}^{2} \Delta x, \\
h_{y 4} & =k_{z}^{2} \Delta y, \quad h_{y 5}=2 k_{z} b_{z} \Delta y, \quad h_{y 6}=k_{z} b_{y}-k_{y} b_{z}+b_{z}^{2} \Delta y, \\
c_{0} & =h_{x 3} h_{x 6}+h_{y 3} h_{y 6}, \\
c_{1} & =h_{x 2} h_{x 6}+h_{x 3} h_{x 5}+h_{y 2} h_{y 6}+h_{y 3} h_{y 5}, \\
c_{2} & =h_{x 1} h_{x 6}+h_{x 2} h_{x 5}+h_{x 3} h_{x 4}+h_{y 1} h_{y 6}+h_{y 2} h_{y 5}+h_{y 3} h_{y 4}, \\
c_{3} & =h_{x 1} h_{x 5}+h_{x 2} h_{x 4}+h_{y 1} h_{y 5}+h_{y 2} h_{y 4}, \\
c_{4} & =h_{x 1} h_{x 4}+h_{y 1} h_{y 4}
\end{aligned}
$$

and obtain

$$
c_{0}+c_{1} t+c_{2} t^{2}+c_{3} t^{3}+c_{4} t^{4}=0
$$

Among the real roots of equation (17), it is necessary to consider only those that satisfy the above restriction: $t \in[0,1]$. Substitute the roots into (16) and obtain the stationary points $\left\{\mathbf{r}_{j}^{*}\right\}_{j=1}^{J}$. Then, we use formula (15) to find the maximal coordinate discrepancy on the segment. This procedure should be repeated for all segments forming $\partial R$, and then formula (14) is enough to calculate the maximal coordinate discrepancy.

Therefore, we proposed an analytical method for calculating the maximal coordinate discrepancy $L_{\infty}(\mathrm{d} ; R)$ in the case when the region of interest $R$ is a union of polygons. The asymptotic complexity of the proposed method is $\Theta(n)$ operations, where $n$ is the total number of vertices of the polygons from $R$. 


\section{Conclusion}

In this paper, we introduce and justify a mathematical model of a system to recognize a fixed structured document from a photograph taken from an arbitrary angle. Within the framework of the introduced mathematical model, we prove that the accuracy criterion for normalization of photographs, which is equal to the maximal coordinate discrepancy in text fields of the document, monotonically depends on the probability of further correct recognition of the entire document. Also, we show that the problem on calculating the maximal coordinate discrepancy is not reduced to the nearest known one, i.e. LFP problem. In addition, we prove the theorem that reduces the problem on maximization of the coordinate discrepancy on a bounded closed set to maximization of the discrepancy on the boundary of the set only. Finally, we obtain an analytical solution to the problem on calculating the maximal coordinate discrepancy on the union of polygons. The results can be used both to construct image normalization methods and to develop image normalization accuracy criteria.

\section{Appendix A: On Maximum of Quasiconvex Function on Bounded Closed Set}

Theorem 3. Let $X \subseteq \mathbb{R}^{n}$ be an arbitrary nonempty set, $f$ be a quasiconvex function defined on $\operatorname{Conv}(X)$ as well:

$$
\operatorname{dom} f \supseteq \operatorname{Conv}(X)
$$

Then

$$
\sup _{X} f=\sup _{\operatorname{Conv}(X)} f
$$

Proof. Denote the supremum of $f$ on $X$ by

$$
s \stackrel{\text { def }}{=} \sup _{X} f
$$

then

$$
f(\mathbf{r} \in X) \leq s .
$$

Taking into account (18), consider all the points of $\operatorname{Conv}(X)$, the value of $f$ at which does not exceed the supremum of $f$ on $X$ :

$$
X_{s} \stackrel{\text { def }}{=}\{\mathbf{r} \in \operatorname{Conv}(X): f(\mathbf{r}) \leq s\}
$$

then

$$
X_{s} \subseteq \operatorname{Conv}(X)
$$

and

$$
f\left(\mathbf{r} \in X_{s}\right) \leq s .
$$

It follows from $X \subseteq \operatorname{Conv}(X)$ and (21) that $X$ satisfies all the restrictions of the definition of $X_{s}(22)$, therefore,

$$
X \subseteq X_{s}
$$


But $X_{s}$ is convex, since $f$ is quasiconvex. Therefore, $X_{s}$ is a convex set containing $X$. Then $\operatorname{Conv}(X) \subseteq X_{s}$ as the smallest convex set containing $X$. Hence, taking into account (23), we have

$$
X_{s}=\operatorname{Conv}(X) \text {. }
$$

It follows from (20) and (25) that $\sup _{X_{s}} f \geq s$, therefore, taking into account (24), we obtain

$$
\sup _{X_{s}} f=s
$$

Statement (19) follows from (20), (26) and (27).

Theorem 3 can be used in both directions: to replace $X$ with (as a rule) a more simple set $\operatorname{Conv}(X)$ and to replace $\operatorname{Conv}(X)$ with (as a rule) the significantly smaller set $X$.

Next, define an extreme point of a convex set $C$ in a real vector space as a point that is not the middle of a segment in $C$.

Theorem 4. Let $X \subseteq \mathbb{R}^{n}$ be a non-empty bounded closed set, $f$ be a quasiconvex function defined on $\operatorname{Conv}(X)$ as well:

$$
\operatorname{dom} f \supseteq \operatorname{Conv}(X)
$$

Then

$$
\sup _{X} f=\sup _{\mathrm{E}(\operatorname{Conv}(X))} f,
$$

where $\mathrm{E}(C)$ is the set of extreme points of the convex set $C$.

Proof. Denote

$$
C \stackrel{\text { def }}{=} \operatorname{Conv}(X) \text {. }
$$

Since the set $X$ is bounded and closed, then the set $C$ is bounded, closed and convex (Caratheodory's theorem [29]). Following Corollary 18.5.1 of the monograph [30], the set $C$ is the convex hull of its extreme points:

$$
C=\operatorname{Conv}(\mathrm{E}(C)) \text {. }
$$

Substitute (29) into (30) and obtain

$$
\begin{gathered}
\operatorname{Conv}(X)=\operatorname{Conv}(\mathrm{E}(\operatorname{Conv}(X))) \Longrightarrow \\
\sup _{\operatorname{Conv}(X)} f=\sup _{\operatorname{Conv}(\mathrm{E}(\operatorname{Conv}(X)))} f .
\end{gathered}
$$

Applying Theorem 3 to both parts of (31), we obtain statement (28).

Theorem 4 is close to statements given in the section "Maxima of convex functions" of the monograph [30], but, unlike these statements, does not require the convexity of $f$ and $X$. In addition, Theorem 4 does not require the connection of the set $X$.

Acknowledgments. The study was carried out with the partial financial support of RFBR within scientific projects no. 17-29-03370 and no. 17-29-03514. 


\section{References}

1. Kunina I.A., Terekhin A.P., Gladilin S.A., Nikolaev D.P. Blind Radial Distortion Compensation from Video Using Fast Hough Transform. ICRMV 2016, SPIE, 2017, vol. 1025308 , pp. 1-7. DOI: $10.1117 / 12.2254867$

2. Shapiro L., Stokman D., Boguslavskiy A.A., Sokolov, S.M. Komp'yuternoe zrenie [Computer Vision]. Moscow, BINOM. Laboratoriya znaniy, 2013. (in Russian)

3. Putjatin E.P., Prokopenko D.O., Pechenaja E.M. [Image Normalization Issues in Projective Transformations]. Radiojelektronika i informatika [Electronics and Informatics], 1998, vol. 2, no. 3, pp. 82-86. (in Russian)

4. Zeynalov R., Velizhev A., Konushin A. [Recovering the Shape of a Page of Text for Correcting Geometric Distortions]. Proceedings of the 19 International Conference GraphiCon-2009, Moscow, 2009, pp. 125-128. (in Russian)

5. Zhukovsky A., Nikolaev D., Arlazarov V., Postnikov V., Polevoy D., Skoryukina N., Chernov T., Shemiakina J., Mukovozov A., Konovalenko I. Segments Graph-Based Approach for Document Capture in a Smartphone Video Stream. ICDAR 2017, IEEE Computer Society, 2017, vol. 1, pp. 337-342. DOI: 10.1109/ICDAR.2017.63

6. Bolotova J.A., Spicyn V.G., Osina P.M. [An Overview of the Algorithms for Detecting Text Areas in Images and Videos]. Komp'yuternaya optika [Computer Optics], 2017, vol. 41, no. 3, pp. 441-452. (in Russian)

7. Shemiakina J.A., Zhukovsky A.E., Faradjev I.A. [The Research of the Algorithms of a Projective Transformation Calculation in the Problem of Planar Object Targeting by Feature Points]. Iskusstvenny intellekt $i$ prinyatie resheniy [Artificial Intelligence and Decision Making], 2017, vol. 2017, no. 1, pp. 43-49. (in Russian)

8. Skoryukina N., Shemiakina J., Arlazarov, V. L., Faradjev I. Document Localization Algorithms Based on Feature Points and Straight Lines. ICMV 2017, SPIE, 2018, vol. $106961 \mathrm{H}$, pp. 1-8. DOI: 10.1117/12.2311478

9. Povolotskiy M.A., Kuznetsova E.G., Khanipov T.M. Russian License Plate Segmentation Based On Dynamic Time Warping. Proceedings ECMS 2017, 2017, pp. 285-291.

10. Skoryukina N.S, Chernov T.S, Bulatov K.B, Nikolaev D. P., Arlazarov V.L. Snapscreen: TVStream Frame Search with Projectively Distorted and Noisy Query. ICMV 2016, SPIE, 2017, vol. 103410Y, pp. 1-5. DOI: 10.1117/12.2268735

11. Youye Xie, Gongguo Tang, Hoff W. Geometry-Based Populated Chessboard Recognition. Tenth International Conference on Machine Vision (ICMV 2017): International Society for Optics and Photonics, 2018, vol. 1069603, pp. 1-5.

12. Arvind C.S., Mishra R., Vishal K., Gundimeda V. Vision Based Speed Breaker Detection for Autonomous Vehicle. Tenth International Conference on Machine Vision (ICMV 2017), 2018, vol. 106960E, pp. 1-9. DOI: 10.1117/12.2311315

13. Dubuisson M.P., Jain A.K. A Modified Hausdorff Distance for Object Matching. Proceedings of 12th International Conference on Pattern Recognition, 1994, vol. 1, pp. 566-568. DOI: $10.1109 /$ ICPR.1994.576361

14. Sim D.G., Kwon O.K., Park R.H. Object Matching Algorithms Using Robust Hausdorff Distance Measures. IEEE Transactions on Image Processing, 1999, vol. 8, no. 3, pp. 425-429. DOI: $10.1109 / 83.748897$

15. Orrite C., Herrero J.E. Shape Matching of Partially Occluded Curves Invariant Under Projective Transformation. Computer Vision and Image Understanding, 2004, vol. 93, no. 1, pp. 34-64. DOI: 10.1016/j.cviu.2003.09.005 
16. Nikolayev P.P. [Projectively Invariant Description of Non-Planar Smooth Figures. 1. Preliminary Analysis of the Problem]. Sensornye sistemy [Sensor System], 2016, vol. 30, no. 4, pp. 290-311. (in Russian)

17. Balickiy A.M., Savchik A.V., Gafarov R.F., Konovalenko I.A. [About Design-Invariant Points of an Oval with a Distinguished External Line]. Problemy peredachi informacii [Information Transfer Issues], 2017, vol. 53, no. 3, pp. 84-89. (in Russian)

18. Savchik A.V., Nikolaev P.P. [Projective Matching Method for Ovals with Two Marked Points]. Informacionnye tehnologii $i$ vychislitel'nye sistemy [Information Technology and Computing Systems], 2018, vol. 2018, no. 1, pp. 60-67. (in Russian)

19. Katamanov S.N. [MTSAT-1R Automatic Geostationary Satellite Image Linking]. Sovremennye problemy distancionnogo zondirovanija Zemli iz kosmosa [Modern Problems of Remote Sensing of the Earth from Space], 2007, vol. 1, no. 4, pp. 63-68. (in Russian)

20. Karpenko S., Konovalenko I., Miller A., Miller B., Nikolaev D. UAV Control on the Basis of 3D Landmark Bearing-Only Observations. Sensors, 2015, vol. 15, no. 12, pp. 29802-29820. DOI: $10.3390 / \mathrm{s} 151229768$

21. Holopov I.S. [Projection Distortion Correction Algorithm for Low-Altitude Shooting]. Komp'yuternaja optika [Computer Optics], 2017, vol. 41, no. 2, pp. 284-290. (in Russian)

22. Legge G.E., Pelli D.G., Rubin G.S., Schleske M.M. Psychophysics of ReadingI. Normal Vision. Vision Research, 1985, vol. 25, no. 2, pp. 239-252. DOI: $10.1016 / 0042-6989(85) 90117-8$

23. Kunina I.A., Gladilin S.A., Nikolaev D.P. [Blind Radial Distortion Compensation in a Single Image Using Fast Hough Transform]. Komp'yuternaja optika [Computer Optics], 2016, vol. 40, no. 3, pp. 395-403. (in Russian) DOI: 10.18287/2412-6179-2016-40-3-395-403

24. Arlazarov V.V., Slavin O.A.E., Uskov A.V.E., Janiszewskinn I.M. Modelling the Flow of Character Recognition Results in Video Stream. Bulletin of the South Ural State University. Series: Mathematical Modelling, Programming and Computer Software, 2018, vol. 11. no. 2, pp. 14-28. DOI: $10.14529 / \mathrm{mmp} 180202$

25. Avriel, M. Nonlinear Programming: Analysis and Methods. North Chelmsford, Courier Corporation, 2003.

26. Charnes A., Cooper, W.W. Programming with Linear Fractional Functionals. Naval Research Logistics Quarterly, 1962, vol. 9, no. 3-4, pp. 181-186. DOI: 10.1002/nav.3800090303

27. Boyd, L. Convex Optimization. Cambridge, Cambridge University Press, 2004. DOI: $10.1017 /$ CBO9780511804441

28. Biswas A., Verma S., Ojha, D.B. Optimality and Convexity Theorems for Linear Fractional Programming Problem. International Journal of Computational and Applied Mathematics, 2017, vol. 12, no. 3, pp. 911-916.

29. Judin D.B. Matematicheskie metody upravlenija $v$ uslovijah nepolnoj informacii [Mathematical Control Methods in Conditions of Incomplete Information]. Moscow, Izdatel'skaya gruppa URSS, 2010. (in Russian)

30. Rokafellar R. Vypuklyj analiz [Convex Analysis]. Moscow, Mir, 1973. (in Russian)

Received November 21, 2019 


\title{
МАКСИМАЛЬНАЯ НЕВЯЗКА КООРДИНАТ КАК КРИТЕРИЙ ТОЧНОСТИ ПРОЕКТИВНОЙ НОРМАЛИЗАЦИИ ИЗОБРАЖЕНИЯ ПРИ ОПТИЧЕСКОМ РАСПОЗНАВАНИИ ДОКУМЕНТОВ
}

\author{
И.А. Коноваленко ${ }^{1,2}$, В.В. Кохан ${ }^{1,2}$, Д.П. Николаев ${ }^{1,2}$ \\ ${ }^{1}$ Институт проблем передачи информации им. А.А. Харкевича РАН, г. Москва, \\ Российская Федерация \\ ${ }^{2}$ OОО Смарт Энджинс Сервис, г. Москва, Российская Федерация
}

\begin{abstract}
Общепринято применение проективной нормализации (частный случай ортокоррекции и коррекции перспективы) к фотографиям документов для их последующего оптического распознавания. При этом неточности нормализации могут приводить к ошибкам распознавания. На сегодняшний день в литературе предложен ряд критериев точности нормализации, однако их соответствие качеству распознавания не исследуется. В данной работе для случая документа фиксированной структуры обосновывается равномерная вероятностная модель ошибок распознавания, в соответствии с которой вероятность верного распознавания символа скачком падает до нуля с ростом невязки координат этого символа. Для этой модели доказано, что критерий точности нормализации изображения, равный максимальной по текстовым полям документа невязке координат, монотонно связан с вероятностью верного распознавания всего документа. Показано, что задача вычисления максимальной невязки координат не сводится к ближайшей известной, т.е. задаче дробно-линейного программирования. Наконец, впервые получено аналитическое решение задачи вычисления максимальной невязки координат на объединении многоугольников.

Ключевые слова: ортокоррекиия; коррекиия перспективы; проективная нормализачия изображений; оптическое распознавание символов; критерии точности; невязка координат; нелинейное программирование.
\end{abstract}

\section{Литература}

1. Kunina, I.A. Blind Radial Distortion Compensation from Video Using Fast Hough Transform / I.A. Kunina, A.P. Terekhin, S.A. Gladilin, D.P. Nikolaev // ICRMV 2016, SPIE. - 2017. V. 1025308. - P. 1-7.

2. Шапиро, Л. Компьютерное зрение / Л. Шапиро, Д. Стокман, А.А. Богуславский, С.М. Соколов. - М.: БИНОМ. Лаборатория знаний, 2013.

3. Путятин, Е.П. Вопросы нормализации изображений при проективных преобразованиях / Е.П. Путятин, Д.О. Прокопенко, Е.М. Печеная // Радиоэлектроника и информатика. 1998. - T. 2, № 3. - С. 82-86.

4. Zeynalov, R. Восстановление формы страницы текста для коррекции геометрических искажений / R. Zeynalov, A. Velizhev, A. Konushin // Proceedings of the 19 International Conference GraphiCon-2009. - M., 2009. - C. 125-128.

5. Zhukovsky, A. Segments Graph-Based Approach for Document Capture in a Smartphone Video Stream / A. Zhukovsky, D. Nikolaev, V. Arlazarov, V. Postnikov, D. Polevoy, N. Skoryukina, T. Chernov, J. Shemiakina, A. Mukovozov, I. Konovalenko // ICDAR 2017, IEEE Computer Society. - 2018. - V. 1. - P. 337-342.

6. Болотова, Ю.А. Обзор алгоритмов детектирования текстовых областей на изображениях и видеозаписях / Ю.А. Болотова, В.Г. Спицын, П.М. Осина // Компьютерная оптика. - 2017. - Т. 41, № 3. - С. 441-452. 
7. Шемякина, Ю.А. Исследование алгоритмов вычисления проективного преобразования в задаче наведения на планарный объект по особым точкам / Ю.А. Шемякина, А.Е. Жуковский, И.А Фараджев // Искусственный интеллект и принятие решений. - 2017. Т. 2017, № 1. - С. 43-49.

8. Skoryukina, N. Document Localization Algorithms Based on Feature Points and Straight Lines / N. Skoryukina, J. Shemiakina, V.L. Arlazarov, I. Faradjev // ICMV 2017, SPIE. 2018. - V. 106961H. - P. 1-8.

9. Povolotskiy, M.A. Russian License Plate Segmentation Based on Dynamic Time Warping / M.A. Povolotskiy, E.G. Kuznetsova, T.M. Khanipov // Proceedings ECMS 2017. - 2017. P. 285-291.

10. Skoryukina, N.S. Snapscreen: TV-Stream Frame Search with Projectively Distorted and Noisy Query / N.S. Skoryukina, T.S. Chernov, K.B. Bulatov, D.P. Nikolaev, V.L. Arlazarov // ICMV 2016, SPIE. - 2017. - V. 103410Y. - P. 1-5.

11. Youye Xie. Geometry-Based Populated Chessboard Recognition / Youye Xie, Gongguo Tang, W. Hoff // Tenth International Conference on Machine Vision (ICMV 2017). - 2018. V. 1069603. - P. 1-5.

12. Arvind, C.S. Vision Based Speed Breaker Detection for Autonomous Vehicle / C.S. Arvind, R. Mishra, K.Vishal, V. Gundimeda // Tenth International Conference on Machine Vision (ICMV 2017). - 2018. - V. 106960E, - P. 1-9.

13. Dubuisson, M.P. A Modified Hausdorff Distance for Object Matching / M.P. Dubuisson, A.K. Jain // Proceedings of 12th International Conference On Pattern Recognition. - 1994. V. 1. - P. 566-568.

14. Sim, D.G. Object Matching Algorithms Using Robust Hausdorff Distance Measures D.G. Sim, O.K. Kwon, R.H. Park // IEEE Transactions on Image Processing. - 1999. V. 8, № 3. - P. 425-429.

15. Orrite, C. Shape Matching of Partially Occluded Curves Invariant Under Projective Transformation / C. Orrite, J.E. Herrero // Computer Vision and Image Understanding. 2004. - V. 93, № 1. - P. 34-64.

16. Николаев, П.П. Проективно инвариантное описание неплоских гладких фигур. 1. Предварительный анализ задачи / П.П. Николаев // Сенсорные системы. - 2016. - Т. 30, № 4. - C. 290-311.

17. Балицкий, А.М. О проективно инвариантных точках овала с выделенной внешней прямой / А.М. Балицкий, А.В. Савчик, Р.Ф. Гафаров, И.А. Коноваленко // Проблемы передачи информации. - 2017. - Т. 53, № 3. - С. 84-89.

18. Савчик, А.В. Метод проективного сопоставления для овалов с двумя отмеченными точками / А.В. Савчик, П.П. Николаев // Информационные технологии и вычислительные системы. - 2018. - Т. 2018, № 1. - С. 60-67.

19. Катаманов, С.Н. Автоматическая привязка изображений геостационарного спутника MTSAT-1R / C.Н. Катаманов // Современные проблемы дистанционного зондирования Земли из космоса. - 2007. - Т. 1, № 4. - С. 63-68.

20. Karpenko, S. UAV Control on the Basis of 3D Landmark Bearing-Only Observations / S. Karpenko, I. Konovalenko, A. Miller, B. Miller, D. Nikolaev // Sensors. - 2015. - V. 15, № 12. - P. 29802-29820.

21. Холопов, И.С. Алгоритм коррекции проективных искажений при маловысотной съёмки / И.С. Холопов // Компьютерная оптика. - 2017. - Т. 41, № 2. - С. 284-290. 
22. Legge, G.E. Psychophysics of Reading. I. Normal Vision / G.E. Legge, D.G. Pelli, G.S. Rubin, M.M. Schleske // Vision Research. - 1985. - V. 25, № 2. - P. 239-252.

23. Кунина, И.А. Слепая компенсация радиальной дисторсии на одиночном изображении с использованием быстрого преобразования Хафа / И.А. Кунина, С.А. Гладинин, Д.П. Николаев // Компьютерная оптика. - 2016. - Т. 40, № 3. - С. 395-403.

24. Arlazarov, V.V. Modelling the Flow of Character Recognition Results in Video Stream / V.V. Arlazarov, O.A.E. Slavin, A.V.E. Uskov, I.M. Janiszewski // Вестник ЮУрГУ. Серия: Математическое моделирование и программирование. - 2018. - Т. 11, № 2. C. $14-28$.

25. Avriel, M. Nonlinear Programming: Analysis and Methods / M. Avriel . - North Chelmsford: Courier Corporation, 2003.

26. Charnes, A. Programming with Linear Fractional Functionals / A. Charnes, W.W. Cooper // Naval Research Logistics Quarterly. - 1962. - V. 9, № 3, 4. - P. 181-186.

27. Boyd, L. Convex optimization / L. Boyd. - Cambridge: Cambridge University Press, 2004.

28. Biswas, A. Optimality and Convexity Theorems for Linear Fractional Programming Problem / A. Biswas, S. Verma, D.B. Ojha // International Journal of Computational and Applied Mathematics. - 2017. - V. 12, № 3. - P. 911-916.

29. Юдин, Д.Б. Математические методы управления в условиях неполной информации / Д.Б. Юдин. - М.: Издательская группа URSS, 2010.

30. Рокафеллар, Р. Выпуклый анализ / Р. Рокафеллар - М.: Мир, 1973.

Иван Андреевич Коноваленко, младший научный сотрудник, лаборатория «Зрительные системы», Институт проблем передачи информации им. А.А. Харкевича PAH; научный сотрудник, программист, ООО Смарт Энджинс Сервис (г. Москва, Российская Федерация), konovalenko@smartengines.com.

Владислав Владимирович Кохан, младший научный сотрудник, лаборатория «Зрительные системы», Институт проблем передачи информации им. А.А. Харкевича РАН; научный сотрудник, программист, ООО Смарт Энджинс Сервис (г. Москва, Российская Федерация), v.kokhan@smartengines.com.

Дмитрий Петрович Николаев, кандидат физико-математических наук, заместитель директора по научной работе, заведующий лабораторией, лаборатория «Зрительные системы», Институт проблем передачи информации им. А.А. Харкевича РАН; технический директор, ООО Смарт Энджинс Сервис (г. Москва, Российская Федерация), dimonstr@iitp.ru.

Поступила в редакиию 21 ноября 2019 г. 